\title{
ASSESSMENT OF PROPERTIES AND DURABILITY OF FLY ASH CONCRETE USED IN KOREAN NUCLEAR POWER PLANTS
}

\author{
MYUNG SUG CHO and JAE MYOUNG NOH* \\ KHNP-Central Research Institute, Korea Hydro \& Nuclear Power Co., LTD \\ 1312-70 Yoseong-daero, Yuseoung-gu, Daejeon, 305-343, Republic of Korea \\ "Corresponding author. E-mail : jmnoh@khnp.co.kr
}

Received July 14, 2010

Accepted for Publication July 26, 2011

\begin{abstract}
Since the opening of the Shin-Kori \#1,2 in 2005, fly ash mixed concrete has been used for NPP concrete structures under construction in Korea with the aim of preventing aging and improving durability. In this paper, the quality suitability of fly ash manufactured in Korea is assessed and the basic physical properties of fly ash mixed concrete and its durability against primary causes of aging are verified through experimental methods. Because of the internal structure filling effect from the pozzolanic reaction of fly ash and the resulting improvements in mechanical performance in such areas as strength and salt damage resistance, the durability of fly ash mixed concrete is shown to be superior. It is judged that this result can be applied in measures not only for improving the safety of NPP structures in operation in Korea but also for implementing effective structure life management should extending the life of structures be needed in the future.
\end{abstract}

KEYWORDS : Fly Ash, Type I Cement, Type V Cement, Durability, Pozzolanic Reaction, Nuclear Power Plants

\section{INTRODUCTION}

Type V cement (sulfate-resistant cement) has been used in nuclear power plant (NPP) structures in Korea since 1978, starting with the Kori NPP \#2. At the time, the main reason for choosing Type $\mathrm{V}$ cement was the lack of technology in Korea to manufacture low-alkali cement that could effectively handle cracks occurring from the alkali-aggregate reaction and the concrete's heat of hydration. Since that time, with the aim of securing durability suitable for structure type and operation environment, Type $\mathrm{V}$ cement has been used in main safety-related structures including containment buildings with consideration of the impact of sulfate attack, alkaliaggregate reaction, heat of hydration, and the related regulations. Korean NPPs are located on the coastline because they use seawater as coolant. It has been pointed out that, although Type $\mathrm{V}$ cement with reduced $\mathrm{C}_{3} \mathrm{~A}$ content has outstanding sulfate resistance, its effectiveness in terms of resistance to chloride, the main ingredient of seawater, is inadequate.

The penetration of sulfate ions within the concrete is limited in depth and their diffusion rate is smaller than that of chloride ions. In addition, since the sulfate concentration of seawater is only $1 / 7$ of the chloride concentration, the sulfate penetration amount is equal to only several tenths of the chloride amount. Therefore, according to recent study results, when constructing structures that will be affected by seawater rather than sulfate damage, instead of using Type $\mathrm{V}$ cement, using Type I cement mixed with admixtures such as fly ash and blast-furnace slag is recommended in consideration of chloride attack. Meanwhile, studies on fly ash mixed concrete in Korea have focused mainly on understanding the initial properties of concrete, such as the workability and strength resulting from the fly ash mixing. However, in order to use fly ash in NPP concrete structures for which safety is the greatest concern, a systematic study must be performed not only on the physical and mechanical properties but also on the comprehensive durability; this study must consider the long-term behavior characteristics, related technical standards and operation environment. Based on this study, a concrete mix design that considers the strength required for use needs to be established.

This paper, therefore, aims to discuss the quality suitability assessment of fly ash being produced in Korea as well as the comprehensive durability of fly ash mixed concrete; this concrete takes into account the technical standards and operation environment of NPP structures. 
Table 1. Physical Properties of Fly Ash Standards

\begin{tabular}{|c|c|c|c|c|c|c|c|c|c|}
\hline \multirow{2}{*}{\multicolumn{3}{|c|}{ Category }} & \multicolumn{2}{|c|}{ ASTM } & \multicolumn{2}{|c|}{ KS } & \multicolumn{3}{|c|}{ JIS } \\
\hline & & & \multirow{2}{*}{$\frac{C}{34}$} & \multirow{2}{*}{$\frac{F}{34}$} & \multirow{2}{*}{$\frac{1}{10}$} & \multirow{2}{*}{$\begin{array}{c}2 \\
40\end{array}$} & \multirow{2}{*}{$\frac{\mathrm{I}}{10}$} & \multirow{2}{*}{$\frac{\text { II }}{40}$} & \multirow{2}{*}{$\begin{array}{l}\text { III } \\
40\end{array}$} \\
\hline \multirow{2}{*}{ Fineness } & \multicolumn{2}{|c|}{ Amount retained on $45 \mu \mathrm{m}$ sieve $(\max \%)$} & & & & & & & \\
\hline & \multicolumn{2}{|c|}{ Specific surface area $\left(\min \mathrm{cm}^{2} / \mathrm{g}\right)$} & - & - & 4500 & 3000 & 5000 & 2500 & 2500 \\
\hline \multicolumn{3}{|c|}{ Density $\left(\mathrm{g} / \mathrm{cm}^{3}\right)$} & - & - & 1.95 & 1.95 & 1.95 & 1.95 & 1.95 \\
\hline \multicolumn{3}{|c|}{ Water requirement $(\max \%)$} & 105 & 105 & - & - & - & - & - \\
\hline \multicolumn{3}{|c|}{ Flow value ratio $(\min \%)$} & - & - & 105 & 95 & 105 & 95 & 85 \\
\hline \multirow{2}{*}{\multicolumn{2}{|c|}{ Strength activity index $(\min \%)$}} & 28 days & 75 & 75 & 90 & 80 & 90 & 80 & 80 \\
\hline & & 91 days & - & - & 100 & 90 & 100 & 90 & 90 \\
\hline \multicolumn{3}{|c|}{ Autoclave expansion (max \%) } & 0.8 & 0.8 & - & - & - & - & - \\
\hline \multicolumn{3}{|c|}{ Drying shrinkage (28 days, max \%) } & 0.03 & 0.03 & - & - & - & - & - \\
\hline \multicolumn{3}{|c|}{$\begin{array}{c}\text { Reactivity with cement alkalies } \\
\text { (Mortar expansion, } 14 \text { days, max \%) }\end{array}$} & 0.02 & 0.02 & - & - & - & - & - \\
\hline
\end{tabular}

Table 2. Chemical Composition of Fly Ash Standards

\begin{tabular}{c|c|c|c|c|c|c|c}
\hline \multirow{2}{*}{ Category } & \multicolumn{2}{|c|}{ ASTM } & \multicolumn{2}{c|}{ KS } & \multicolumn{3}{c}{ JIS } \\
\cline { 2 - 8 } & $\mathrm{C}$ & $\mathrm{F}$ & 1 & 2 & $\mathrm{I}$ & $\mathrm{II}$ & $\mathrm{III}$ \\
\hline $\mathrm{S}+\mathrm{A}+\mathrm{F}(\min \%)^{*}$ & 50 & 70 & - & - & - & - & - \\
\hline $\mathrm{SiO}_{2}(\max \%)$ & - & - & 45 & 45 & 45 & 45 & 45 \\
\hline $\mathrm{SO}_{3}(\max \%)$ & 5 & 5 & - & - & - & - & - \\
\hline Moisture $(\max \%)$ & 3 & 3 & 1 & 1 & 1 & 1 & 1 \\
\hline L. O. I. $(\max \%)^{* *}$ & 6 & 6 & 3 & 5 & 3 & 5 & 8 \\
\hline${ }^{*} \mathrm{SiO}_{2}+\mathrm{Al}_{2} \mathrm{O}_{3}+\mathrm{Fe}_{2} \mathrm{O}_{3}{ }^{* *}$ & \multicolumn{7}{|c|}{ Loss on Ignition }
\end{tabular}

\section{FLY ASH SUITABILITY ASSESSMENT}

\subsection{Fly Ash Quality Standard}

Since the quality of fly ash changes depending on the coal type, combustion conditions and boiler type, fly ash that satisfies the related quality standard must be used when using it as a concrete admixture [1]. Generally, the chemical and physical properties of fly ash affect concrete characteristics such as flow, air content and strength, as well as chemical resistance. Therefore, quality standards for the main categories are presented, as can be seen in Tables 1 2, for Korea (KS L 5405), the US (ASTM C 618) and Japan (JIS A 6201). Particularly in Korea, to promote the use of fly ash as an admixture and to apply it to highquality concrete and special-purpose concrete, its quality was classified into two grades, Type 1 and Type 2, by revising the related standard from 2004.

Of the fly ash chemical components, the unburned carbon measured by loss on ignition has the greatest impact on concrete quality. The unburned carbon is composed of complex micro-pore structures, and because its specific surface area is 100 times larger than that of cement, it has the property of easily absorbing chemical admixtures such as $\mathrm{AE}$ agent and plasticizers with just a small amount. Accordingly, when fly ash with high loss on ignition is used, it can have a harmful effect on the concrete quality, leading to such problems as a reduction of the strength and freezing and thawing resistance because of the decrease in flow and air content. The greater the loss on ignition, the greater the amount of $\mathrm{AE}$ agent needed to entrain the required amount of air; however, if the loss on ignition is less than 5\%, the increase amount is not large [2].

The relationship between the loss on ignition and the mortar flow was reported being one in which the tendency of mortar flow decreases as the loss on ignition increases [3]. As mentioned above, when fly ash with large loss on ignition is used, because it has a harmful impact on airentrainment and flow, a product that satisfies the given quality standard must be used. Hence, ASTM requires the base value to be less than $6.0 \%$; on the other hand, $\mathrm{KS}$ and JIS require a value in a 3.0 8.0\% range depending on the quality grade. As such, the base value of loss on ignition differs according to the given standard, but since a smaller loss on ignition has a less harmful impact on concrete, KS standard can be said to be more conservative than that of ASTM.

Of the fly ash's physical properties, fineness is an important quality that affects the pozzolanic reaction and flow of concrete. ASTM adopts the sieve analysis method of requiring $45 \mu \mathrm{m}$ sieve residue, whereas KS and JIS adopt both the sieve analysis and the specific surface area 
Table 3. Composition and Properties of Fly Ash used

\begin{tabular}{|c|c|c|c|c|}
\hline \multirow{2}{*}{\multicolumn{2}{|c|}{ Category }} & \multicolumn{2}{|c|}{ Standard } & \multirow[b]{2}{*}{ Result } \\
\hline & & $\begin{array}{c}\text { ASTM } \\
\text { Grade F }\end{array}$ & $\begin{array}{c}\text { KS } \\
\text { Type } 2\end{array}$ & \\
\hline \multicolumn{2}{|l|}{$\mathrm{S}+\mathrm{A}+\mathrm{F}(\%)$} & $>70$ & - & 87.48 \\
\hline \multicolumn{2}{|l|}{$\mathrm{SiO}_{2}(\%)$} & - & $>45$ & 65.3 \\
\hline \multicolumn{2}{|l|}{$\mathrm{SO}_{3}(\%)$} & $<5.0$ & - & 0.51 \\
\hline \multicolumn{2}{|c|}{ Moisture (\%) } & $<3.0$ & $<1.0$ & 0.07 \\
\hline \multicolumn{2}{|c|}{$45 \mu \mathrm{m}$ sieve residue $(\%)$} & $<34$ & - & 5.7 \\
\hline \multicolumn{2}{|c|}{ Specific surface area $\left(\mathrm{cm}^{2} / \mathrm{g}\right)$} & - & $>3000$ & 3442 \\
\hline \multicolumn{2}{|c|}{ Density $\left(\mathrm{g} / \mathrm{cm}^{3}\right)$} & - & $>1.95$ & 2.27 \\
\hline \multirow{2}{*}{ Activity index (\%) } & 7 days & $>75$ & - & 89 \\
\hline & 28 days & $>75$ & $>90$ & 94 \\
\hline \multicolumn{2}{|c|}{ Autoclave expansion (\%) } & $<0.8$ & - & 0.1 \\
\hline
\end{tabular}

methods. In the relationship between the specific surface area of the fly ash and the $45 \mu \mathrm{m}$ sieve residue, it has been reported that the $45 \mu \mathrm{m}$ sieve residue tends to decrease as the specific surface area gets larger $[4,5]$. Generally, the flow of concrete increases in the initial stage, and then deceases due to the gain of viscosity if the fineness is large. However, the initial strength and durability are improved.

\subsection{Quality Assessment of Fly Ash Used}

In this paper, quality verification tests based on ASTM C618 and KS L5405 standards were performed on the fly ash produced at the refining plant of the Samcheonpo coal combustion power plant in Korea. The results, as can be seen in Table 3, were found to meet the requirements of the related standards for the chemical and physical categories.

In Korea, the fluctuation of fly ash quality in the past was a large restricting factor regarding its use as a concrete admixture. Since the mid-1990s, however, fly ash satisfying a fixed quality standard has been produced as a result of operating refining plants. Hence, if a quality standard is fixed and applied in the process of purchasing the fly ash to be used in an NPP, it is deemed there will be no quality fluctuation impact on the concrete.

\section{PROPERTY OF FLY ASH CONCRETE}

\subsection{Fly Ash Replacement Ratio}

The replacement ratio of the fly ash (\% of cement weight) used in concrete must be determined based on a consideration of the structure and operating environment. In this paper, heat of hydration, strength development,
Table 4. Suitable Fly Ash Replacement Ratio

\begin{tabular}{|c|c|c|}
\hline Category & Criteria & Replacement ratio \\
\hline Heat of hydration & $\begin{array}{c}\text { 70cal/g (7 days) } \\
\text { satisfaction } \\
\text { Lower than Type V }\end{array}$ & $\mathbf{2 0 \%}, 25 \%, 30 \%$ \\
\hline $\begin{array}{c}\text { Strength } \\
\text { development }\end{array}$ & Higher than Type V & $10 \%, 15 \%, \mathbf{2 0 \%}$ \\
\hline $\begin{array}{l}\text { Related code } \\
\text { ACI } 301,318\end{array}$ & $\begin{array}{l}\text { Maximum } 25 \% \\
\text { Minimum } 15 \%\end{array}$ & $15 \%, \mathbf{2 0 \%}, 25 \%$ \\
\hline Economic feasibility & $\begin{array}{c}\text { Meeting all the } \\
\text { conditions above } \\
\text { with largest amount }\end{array}$ & $20 \%$ \\
\hline
\end{tabular}

related technical criteria and economic feasibility were examined in order to determine the suitable fly ash replacement ratio for Korean NPP concrete structures.

With respect to the heat of hydration, the test results showed $20 \%, 25 \%$ and $30 \%$ to be the replacement ratios that satisfy both the limitations applied to cement used in Korean NPP structures and the heat of hydration equivalent to that of the existing Type $\mathrm{V}$ cement in use. For strength development, $10 \%, 15 \%$ and $20 \%$ were shown to be satisfactory as replacement ratios with strength higher than that of Type $\mathrm{V}$ cement, while $15 \%, 20 \%$ and $25 \%$ were shown to satisfy the criteria. As for economic feasibility, the highest replacement ratio that satisfied all the above conditions was chosen in order to use as much fly ash as possible, because fly ash is more economically efficient than cement. As can be seen in Table 4, $20 \%$ was chosen as the suitable fly ash replacement ratio that satisfies all of the above conditions.

The cement, aggregate, super plasticizer, and AE agent used in this paper are the materials used in the construction of the Yonggwang NPP \#5,6 in Korea, while the fly ash used was produced at the Samcheonpo coal combustion power plant.

The basic concrete mix proportion used in Korean NPP structures, which proportion satisfies the selected $20 \%$ replacement ratio criterion, is given in Table 5. This mix proportion was used to prepare the specimens in order to compare the performance of each type of concrete.

\subsection{Compressive Strength Assessment}

The compressive strength assessment, based on the ASTM C39 method, was performed on all mix proportions. The results are given in Figs. 1 2. In the case of $20 \%$ fly ash replacement, the compressive strength after seven days was smaller than that of concrete using only Type I or Type V cement; however, the strength development gradually increased thereafter due to the pozzolanic reaction, and at 91 days the strength was shown to be greater than that of concrete using only Type I or Type V 
Table 5. Basic Concrete Mix Proportion

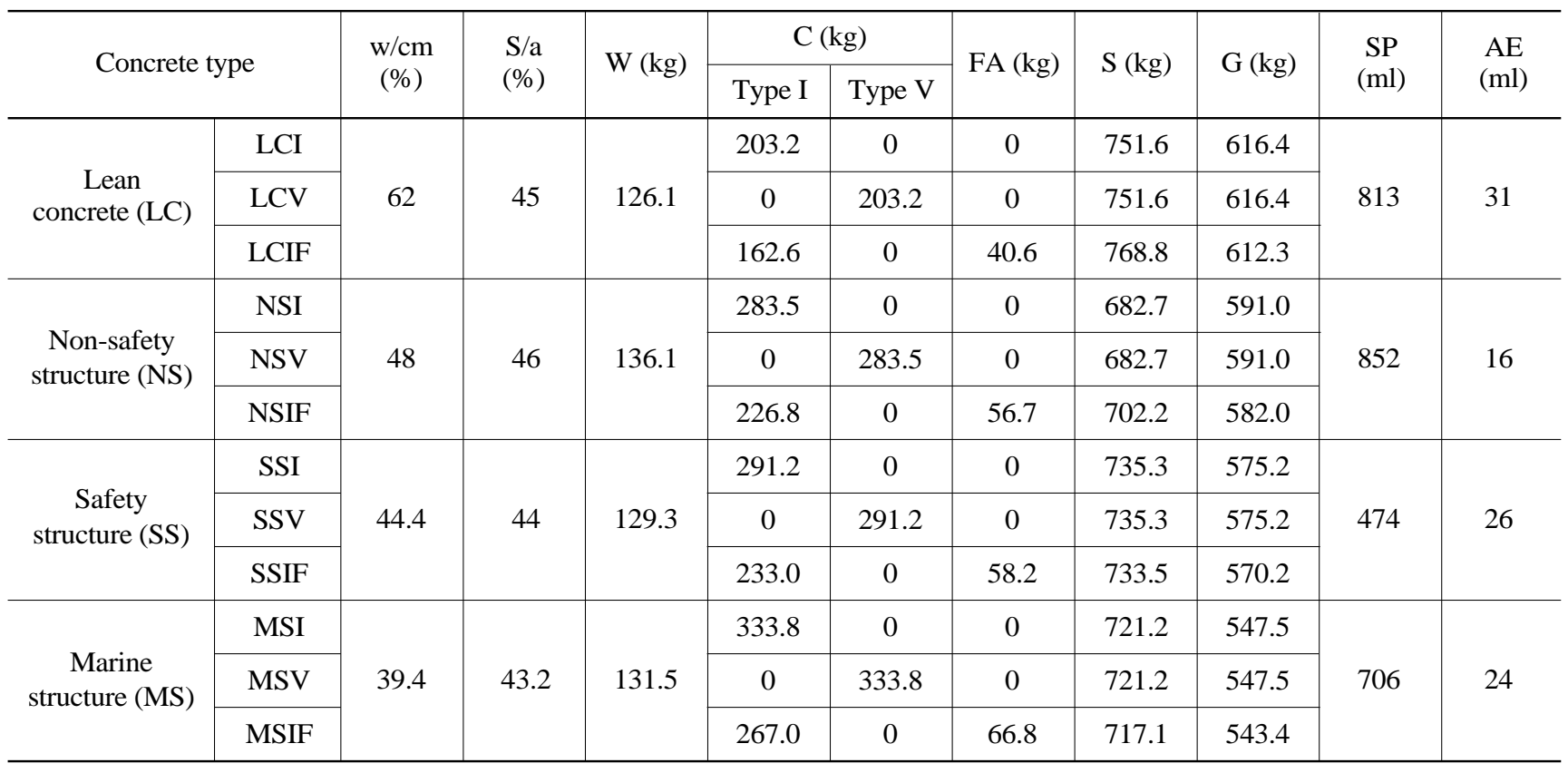

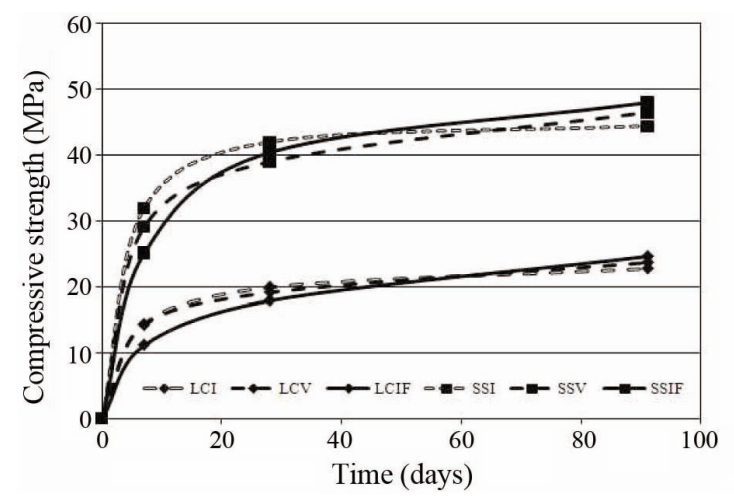

Fig. 1. Concrete Compressive Strength (LC \& SS)

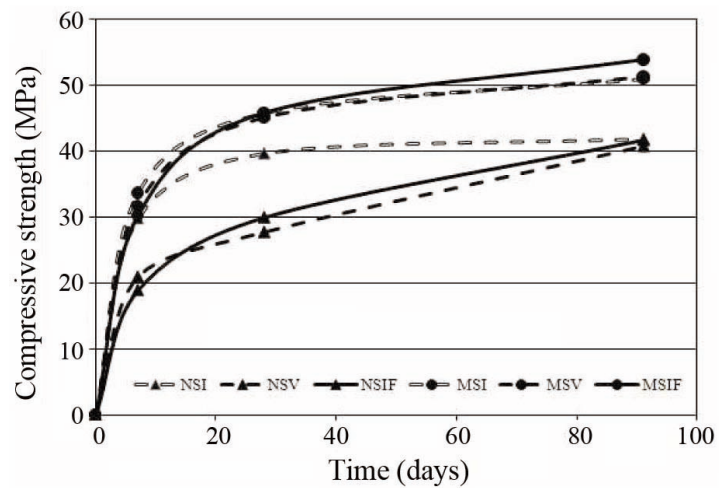

Fig. 2. Concrete Compressive Strength (NS \& MS) cement. Therefore, when fly ash is used, the strength during the initial seven days is slightly lower, but after the age of 91 days (the design strength period for Korean NPP concrete structures) the strength development effect is superior to that of the concrete using only Type I or Type V cement.

\subsection{Heat of Hydration Assessment}

To assess the heat of hydration of the fly ash mixed concrete, tests using the adiabatic temperature rise test apparatus were performed on Type I and Type V cement; as well, tests on Type I plus $10 \%, 15 \%$ and $20 \%$ ash fly were performed with the safety structure concrete used in Korean NPP containment buildings as the target. There are several methods for calculating the heating value of concrete, but because the method based on the adiabatic temperature rise test apparatus, used in this paper, directly measures the heating state and is simple to use, it is widely utilized for predicting temperature rise of mass concrete. The results from the adiabatic temperature rise tests are expressed in an exponential function form, as shown in Eq. (1).

$$
T=K\left(1-e^{-a_{\mathrm{t}} t_{d}}\right)
$$

The results are given in Figs. 3 4. As the replacement ratio of the fly ash increases, the heat of hydration decreases. Concrete with $20 \%$ fly ash replacement has the lowest value for the maximum adiabatic temperature rise and showed a more advantageous result than that of the concrete that used Type V cement. Because the concrete with $20 \%$ fly ash replacement is more advantageous in terms of heat 
Table 6. Fly Ash Mixed Concrete Durability Test Summary

\begin{tabular}{|c|c|c|c|c|}
\hline Test category & Test conditions & Measurement category & Measurement period & Specimen size \\
\hline Chloride & $\begin{array}{c}\text { Immersion } \\
\text { in } 3.6 \% \mathrm{NaCl} \text { solution }\end{array}$ & $\begin{array}{l}\text { Chloride diffusion } \\
\text { coefficient }\end{array}$ & $28,60,91$ days & $10 \times 10 \times 15 \mathrm{~cm}$ \\
\hline Carbonation & $\begin{array}{c}\mathrm{CO}_{2} \text { concentration: } 10 \% \\
\text { Temperature: } 30^{\circ} \mathrm{C} \\
\text { Humidity: } 50 \%\end{array}$ & $\begin{array}{c}\text { Carbonation depth } \\
\text { Carbonation coefficient }\end{array}$ & $7,28,60,91$ days & $10 \times 10 \times 15 \mathrm{~cm}$ \\
\hline Sulfate & $\begin{array}{c}\text { Immersion } \\
\text { in } 10 \% \mathrm{Na}_{2} \mathrm{SO}_{4} \text { solution }\end{array}$ & Length change & $28,60,91$ days & $10 \times 10 \times 40 \mathrm{~cm}$ \\
\hline Freezing and thawing & $\begin{array}{l}\text { ASTM C } 666 \\
\text { (air freezing water } \\
\text { thawing) }\end{array}$ & $\begin{array}{l}\text { Relative dynamic } \\
\text { modulus of elasticity }\end{array}$ & $\begin{array}{l}\text { Every } 30 \text { cycles } \\
\text { up to } 300 \text { cycles }\end{array}$ & $10 \times 10 \times 40 \mathrm{~cm}$ \\
\hline
\end{tabular}

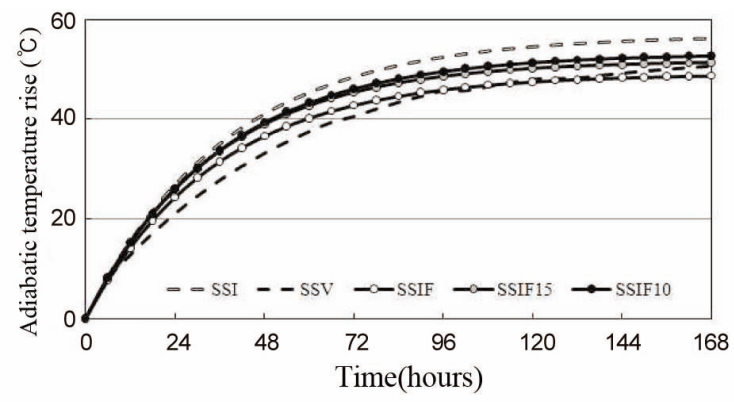

Fig. 3. Adiabatic Temperature Rise Test Results

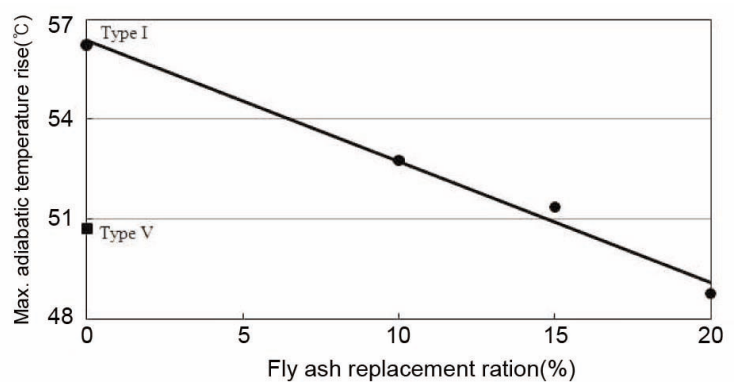

Fig. 4. Max. Adiabatic Temperature Rise

of hydration than is the concrete that used Type V cement, it is expected to reduce concrete cracks, which occur due to the internal temperature rise during the hydration reaction.

\subsection{Creep Assessment}

Most nuclear containment buildings in Korea are prestressed concrete structures. Concrete creep is one of the most important design factors because creep has the greatest impact on estimating the tensile force of tendons and loss of prestress. Accordingly, creep tests were performed on SSI, SSV, and SSIF concrete, which are types of safety structure concrete used in containment buildings. Results are shown in Table 5. As for the test

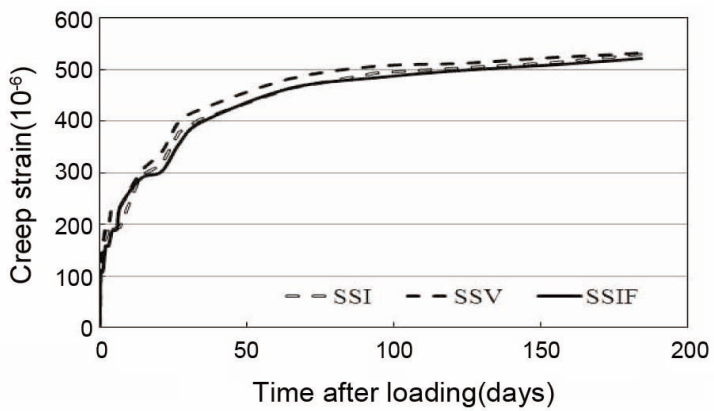

Fig. 5. Creep Curve of Concrete

method, the standard curing conforming to ASTM C512 was performed for seven days using a $\varnothing 150 \times 300 \mathrm{~mm}$ specimen; sample was then sealed with paraffin to prevent the concrete surface moisture evaporation. As for the creep load, $35 \%$ of the compressive strength was applied. The creep conditions were set at a temperature of $23 \pm 1.7^{\circ} \mathrm{C}$ and humidity of $50 \pm 5 \%$; the strain was measured from the specimen at intervals of 28 days for 6 months.

The results are presented in Fig. 5. Creep strain is shown to be smaller for SSIF concrete than for SSI or SSV concretes. Less strain was shown in the concrete that used fly ash because the modulus of elasticity increased as the inner structure became denser due to the pozzolanic reaction; further, the cement paste that affects creep was reduced due to the fly ash replacement. Therefore, SSIF concrete is judged to be more advantageous than the existing Korean NPP concrete, SSV, in terms of creep strain.

\section{DURABILITY ASSESSMENT}

To assess the durability of the fly ash mixed concrete, verification tests, as shown in Table 6, were performed for the main durability factors of Korean NPP concrete structures by using concrete specimens. 


\subsection{Chloride Attack Resistance Assessment}

The $100 \times 100 \times 150 \mathrm{~mm}$ specimens were de-molded after one day and placed under standard curing for 28 days in water at $23^{\circ} \mathrm{C}$; five sides were coated with epoxy in order to induce the chloride ion penetration in one direction. The concentration of chloride contained in the seawater differs depending on the region, but, in general it is $3 \sim 4 \%$. As a representative concentration, a $3.6 \%$ solution of $\mathrm{NaCl}$ was used in this assessment test. The specimens were immersed in a solution of $3.6 \% \mathrm{NaCl}$ and, at days 28, 60 and 91, after taking a $40 \mathrm{~g}$ sample from the specimen surface at depth intervals of $15 \mathrm{~mm}$, the water-soluble chloride ion amount was measured using the ion-electrode method.

Figs. 6 7 show the chloride diffusion coefficients derived from the measured chloride amount by using Fick's diffusion equation. The chloride diffusion coefficients are increasing in the order of Type I $+20 \%$ fly ash < Type I $<$ Type V. The chloride attack resistance increases with the use of fly ash because of the pore structure tightening and water permeability reduction resulting from the pozzolanic reaction. The chloride attack resistance of the specimen that used Type $\mathrm{V}$ cement is the weakest because it contains a smaller amount of $\mathrm{C}_{3} \mathrm{~A}$, which is related to the production of Friedel's salt in comparison with Type I cement. In addition, the chloride penetration speed decreases as the strength increases regardless of cement type or fly ash replacement, because the microstructure becomes denser and deters the chloride ion penetration.

As can be seen from the above test results, the chloride diffusion speed was found to be reduced at all strength levels for fly ash mixed concrete in comparison with the existing Korean NPP concrete, which uses Type V cement. Accordingly, when fly ash is used, application of concrete with durability superior to that of existing concrete in terms of chloride attack resistance is made possible.

\subsection{Carbonation Resistance Assessment}

The $100 \times 100 \times 150 \mathrm{~mm}$ specimens were de-molded after one day and placed under standard curing for 28 days in water at $23^{\circ} \mathrm{C}$. Five sides were coated with epoxy to induce the carbon dioxide penetration in one direction. Since the carbonation of concrete is affected by the concentration of carbon dioxide, and by the temperature and humidity, the conditions in this acceleration were set at $10 \%$ carbon dioxide concentration, $30^{\circ} \mathrm{C}$ temperature and $50 \%$ humidity. The specimens on the carbonation acceleration were split into two at days 7, 28, 60 and 91, and then $1 \%$ phenolphthalein solution was sprayed and the carbonation depth was measured. Figs. 8 9 show the carbonation speed coefficient, converted from the measured carbonation depths. Here, the carbonation speed coefficient refers to the ratio of the carbonation depth and the square root of age.

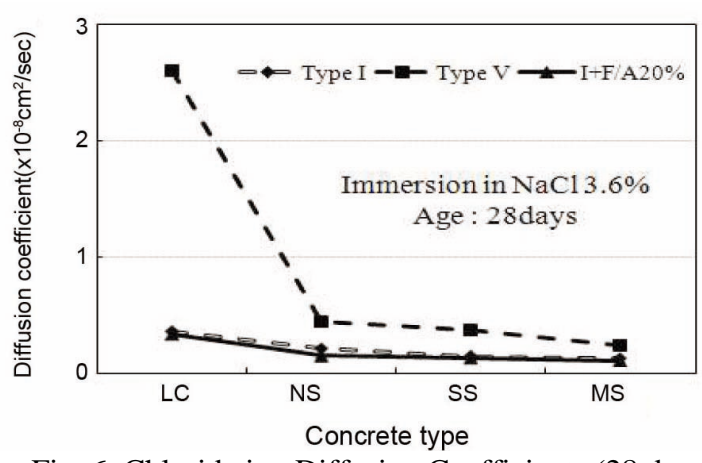

Fig. 6. Chloride ion Diffusion Coefficients (28 days)

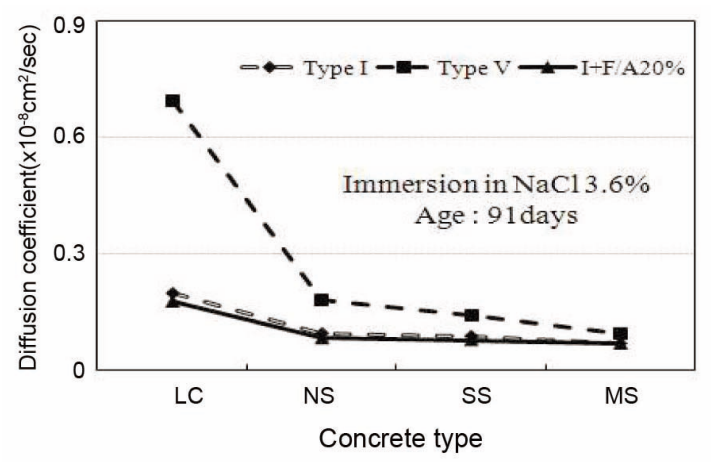

Fig. 7. Chloride ion Diffusion Coefficients (91 days)

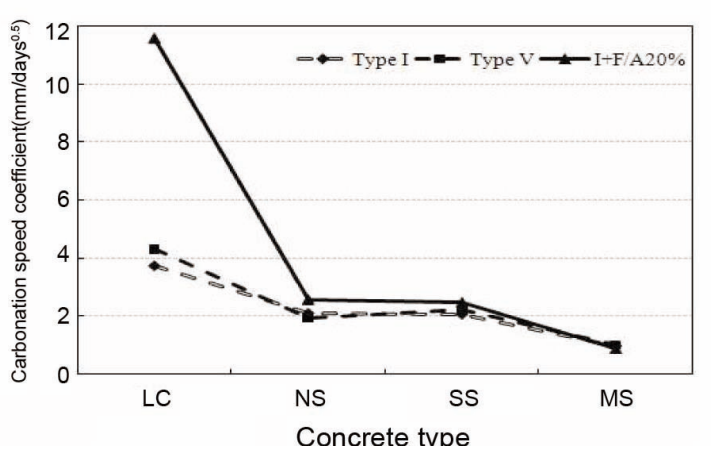

Fig. 8. Carbonation Speed Coefficients (28 days)

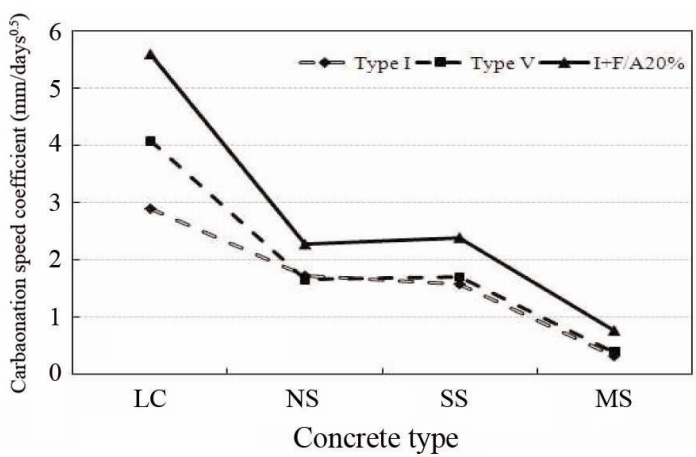

Fig. 9. Carbonation Speed Coefficients (91 days) 
The carbonation speed increases regardless of the strength and age, in the order of Type I < Type $\mathrm{V}<$ Type I $+20 \%$ fly ash. The carbonation speed of the fly ash mixed concrete increases because of the reduction in the cement amount due to the replacement by fly ash and due to the decrease in the $\mathrm{pH}$ of the pore solution of the hardened concrete, which results from the consumption of alkaline $\mathrm{Ca}(\mathrm{OH})_{2}$ by the pozzolanic reaction. In addition, the carbonation speed decreases as the strength and age increase, regardless of cement type, and this tendency is particularly noticeable in fly ash mixed concrete. When fly ash is used at low strength as LC, the resulting compound is somewhat disadvantageous in terms of carbonation compared to Type V cement. However, considering the fact that the main safety-related concrete structures of Korean NPPs use concrete with a design standard age of 91 days and a strength of 5,000 psi or greater, the impact on the structures in terms of carbonation is judged to be small. The long-term durability that results from carbonation was predicted using Eq. (2). Eq. (2) defines the termination of the concrete service life due to carbonation as the point when the carbonation depth reaches the rebar; the equation uses the described acceleration test results as the carbonation depths.

$$
\begin{aligned}
X_{c}= & (2.823-0.854 \log C) \cdot e^{\left(8.3953-\frac{2713}{T}\right)} \times \\
& \left(\frac{H(100-H)(140-H)}{19200}\right) \times\left(0.0303 \frac{w}{c m}-1.0187\right) \times \\
& \alpha_{C} \times \sqrt{C \cdot t_{y}}
\end{aligned}
$$

Fig. 10 presents the prediction results, based on Eq. (2), for long-term durability with respect to carbonation. Even for lean concrete with a high carbonation speed, it was predicted that, in terms of long-term durability, carbonation to the depth of the rebar during the usage life of the concrete will not occur. The greater the concrete strength, the more this tendency is clearly noticeable. That is, when concrete with a water-cementitious material ratio of less than $50 \%$, like the concrete used in Korean NPP structures, is used, even if fly ash, which is

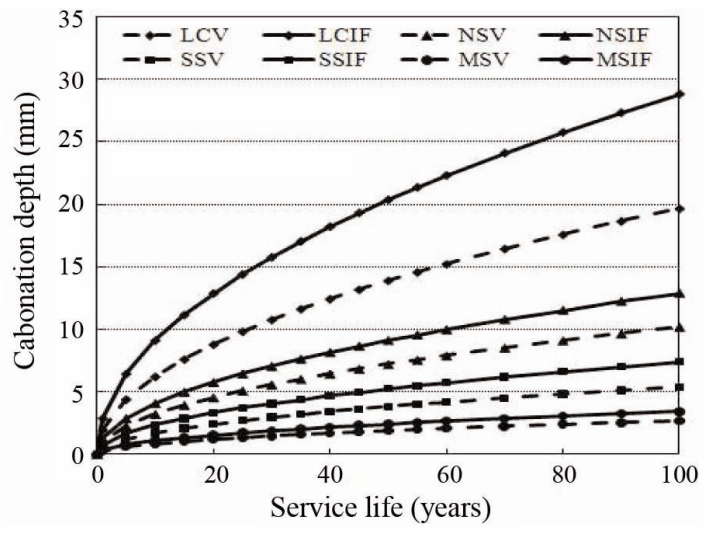

Fig. 10. Carbonation Depth Prediction (91 days) somewhat disadvantageous in terms of carbonation, is used, the denser concrete structure resulting from the pozzolanic reaction can deter the carbon dioxide and oxygen penetration and, consequently, it is deemed that there will be no rebar corrosion problem arising from carbonation.

\subsection{Sulfate Resistance Assessment}

The $100 \times 100 \times 400 \mathrm{~mm}$ specimens were de-molded after one day and placed under standard curing for 28 days in water at $23^{\circ} \mathrm{C}$, in accordance with ASTM C1012. A $5 \%$ aqueous solution of $\mathrm{Na}_{2} \mathrm{SO}_{4}$ was used in ASTM $\mathrm{C} 1012$, but a $10 \%$ solution was used in this test to accelerate the process. The length changes were measured at days 28, 60 and 91

Figs. 11 12 show the sulfate resistance test results. The resistance against sulfate increases in the order of

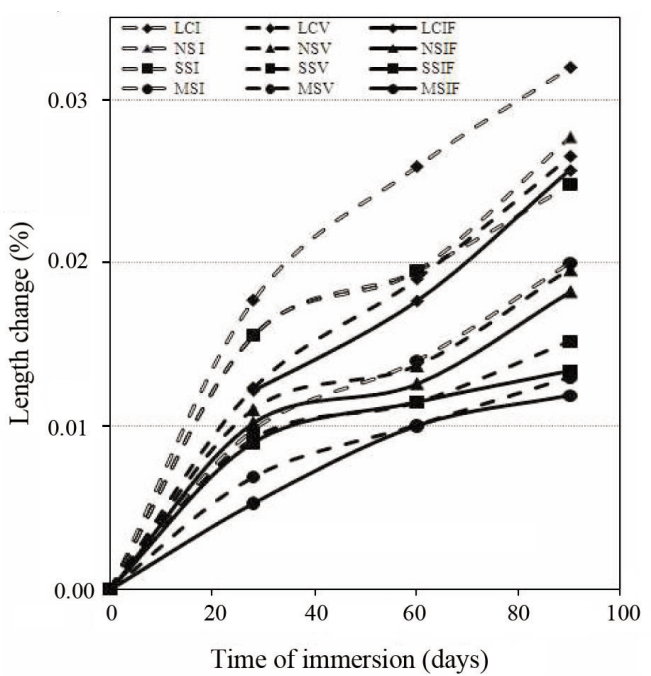

Fig. 11. Sulfate Resistance Test Result (28 days)

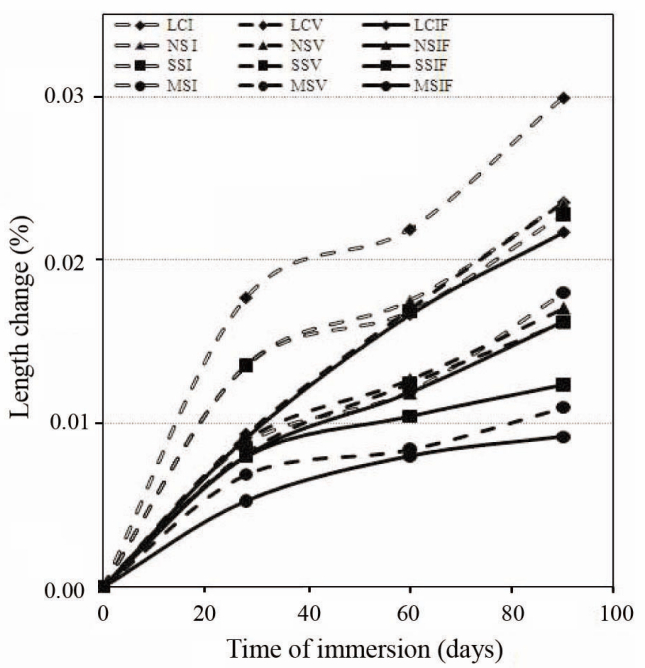

Fig. 12. Sulfate Resistance Test Result (91 days) 


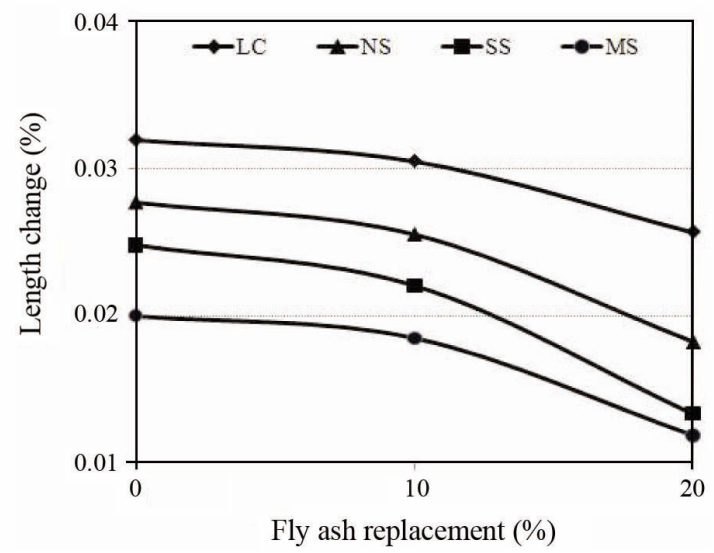

Fig. 13. Sulfate Resistance with Respect to Fly Ash Replacement

Type I < Type V < Type I + 20\% fly ash. For the concrete that used Type $\mathrm{V}$ cement, since the amount of $\mathrm{C}_{3} \mathrm{~A}$, which reacts with the sulfate to produce the needle-like crystal ettringite, is small, this concrete is assessed to have sulfate resistance superior to that of the concrete made of Type I cement. As for the concrete using fly ash, it is assessed to have a sulfate resistance superior to that of the concrete that used Type $\mathrm{V}$ cement because the $\mathrm{Ca}(\mathrm{OH})_{2}$, which is easily eroded by the sulfate ions, is reduced by the pozzolanic reaction and the hardening structure becomes denser. As can be seen from these test results, application of concrete with sulfate resistance superior to that of the concrete that used Type $\mathrm{V}$ cement is possible when fly ash is used.

Fig. 13 shows the results of the test implemented to analyze the impact of fly ash replacement. The higher the replacement ratio within the range of $0 \sim 20 \%$, the better the assessed sulfate resistance.

\subsection{Freezing and Thawing Resistance Assessment}

After the standard curing of the $100 \times 100 \times 400 \mathrm{~mm}$ specimens, the test was performed using the air freezing and water thawing method of ASTM C666. For the test, the temperature range was set at $-18 \sim+4.5^{\circ} \mathrm{C}$ and time of 1 cycle at 2 hours and 40 minutes. The relative dynamic modulus of elasticity was measured by ultrasonic waves every 30 cycles up to 300 cycles. Figs. 14 15 show the freezing and thawing resistance test results.

In the case of entraining an equal amount of air by increasing the AE agent amount, the results showed that the freezing and thawing resistance of the fly ash mixed concrete was most outstanding. It is known that using fly ash is disadvantageous in terms of freezing and thawing resistance because the $\mathrm{AE}$ agent is absorbed by the high specific surface area, making air entrainment difficult and leading to irregular air pore structure formation [6]. However, if the same amount of air is entrained by

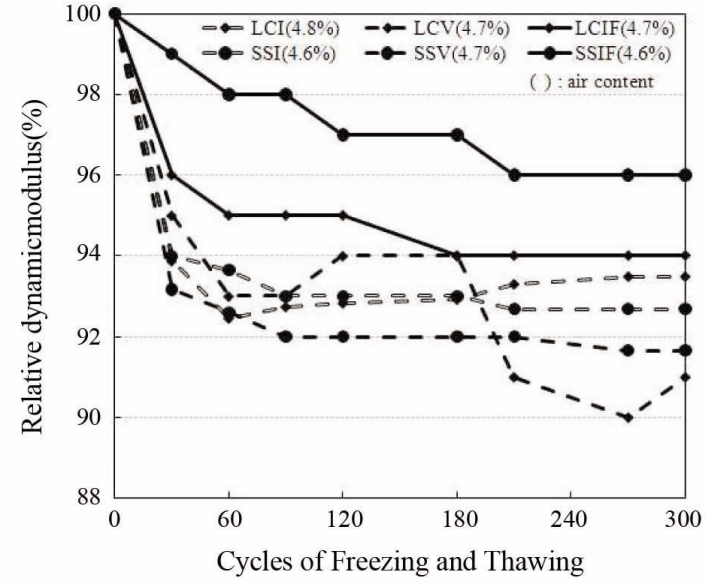

Fig. 14. Relative Dynamic Modulus with Cycles of Freezing and Thawing (28 days, LC and SS)

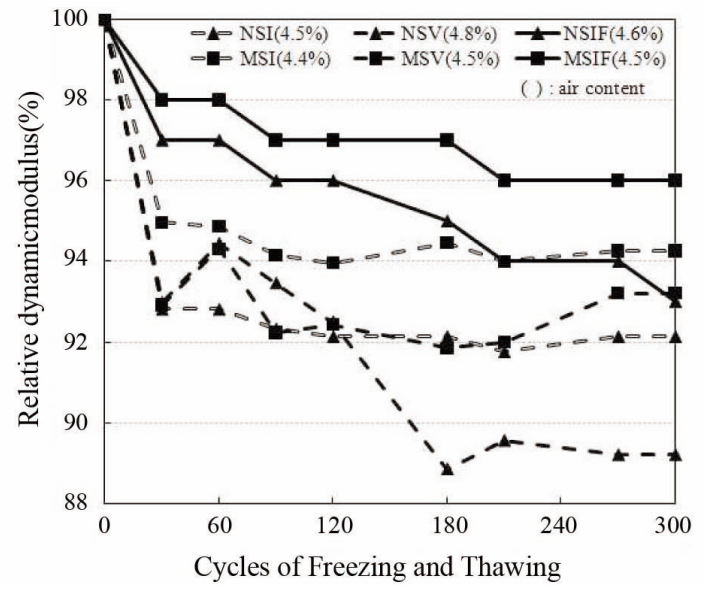

Fig. 15. Relative Dynamic Modulus with Cycles of Freezing and Thawing (28 days, NS and MS)

increasing the AE agent amount, there is no impact on the freezing and thawing resistance even if fly ash is used. The improvement in freezing and thawing resistance resulting from the increase in strength and age is due to the increased strength of the hardening cement and the reduction of free water that can freeze.

When an appropriate amount of air is entrained in the concrete, regardless of the fly ash replacement ratio, the freezing and thawing resistance is shown to be outstanding, with a relative dynamic modulus of elasticity at $95 \%$ or higher. The replacement ratios of $15 \%$ and $20 \%$ displayed similar freezing and thawing resistance but showed improvement over the case of not using fly ash. For replacement ratios of $25 \%$ and $30 \%$, the freezing and thawing resistance was similar to that obtained when not using fly ash [7]. Therefore, in the case of fly ash mixed concrete, when an equal amount of the AE agent is used, the freezing and thawing resistance is somewhat reduced 


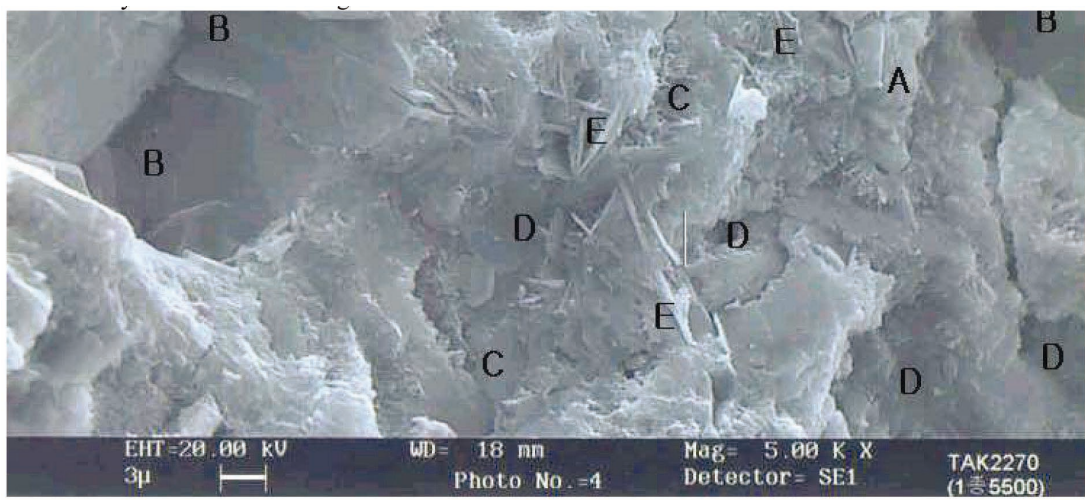

(a) SSI Concrete

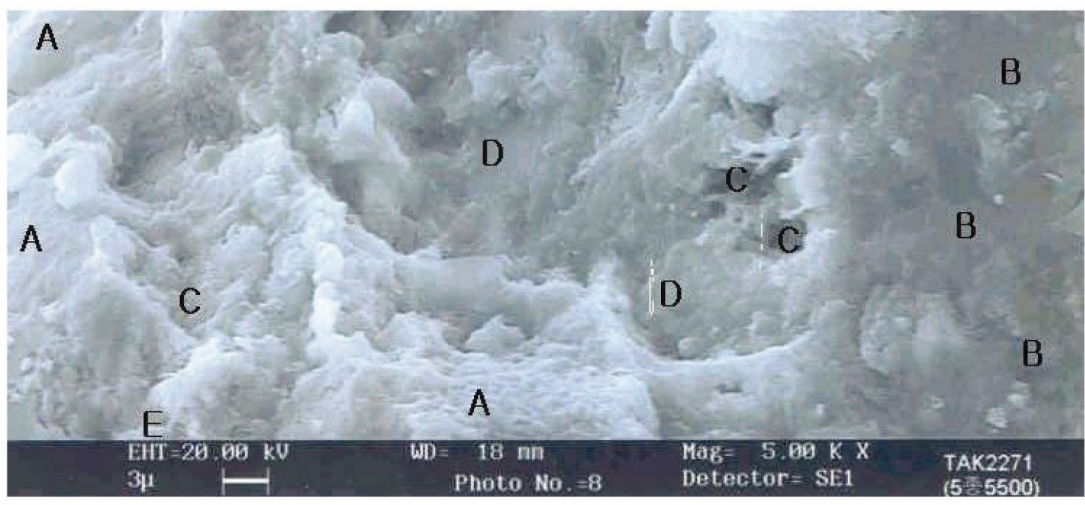

(b) SSV Concrete

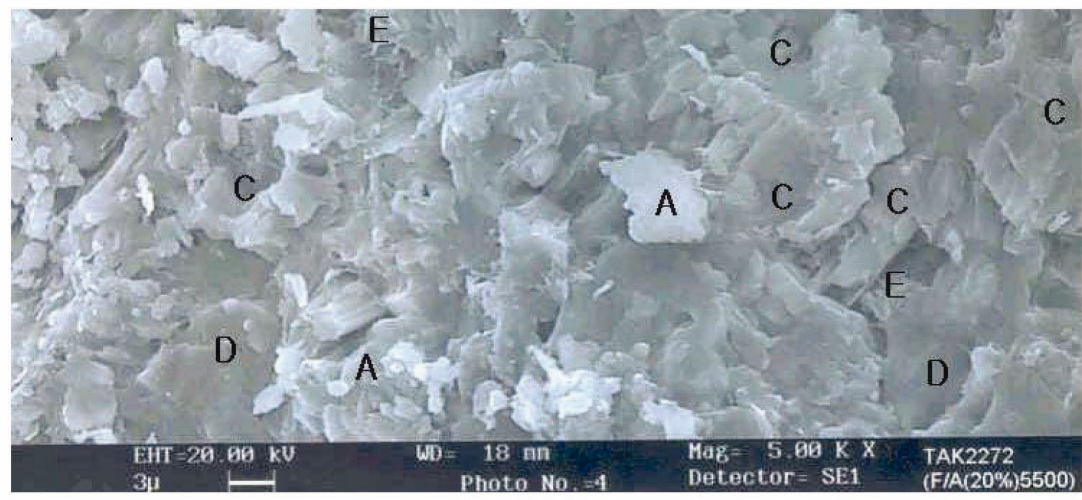

(c) SSIF Concrete

Fig. 16. SEM (Scanning Electron Microscopy) of Hardened Concrete (SS, 91 days) ; A: C-S-H gel, B: $\mathrm{Ca}(\mathrm{OH})_{2}$, C: gel pore, D: capillary pore, E: ettringite

because of the tendency to absorb the AE agent, but the durability requirement is satisfied. If the same amount of air can be obtained, then it is possible to make concrete with durability superior to that of the existing concrete.

\subsection{Micro Structure of Fly Ash Mixed Concrete}

SEM and porosity analysis were implemented in order to assess the changes in the inner micro structure of the concrete resulting from using fly ash.

Fig. 16 shows SEM photography of SS concrete that has been cured for 91 days. In the case of the fly ash mixed concrete, $\mathrm{Ca}(\mathrm{OH})_{2}$ is invisible because of the pozzolanic reaction; instead, a dense $\mathrm{C}-\mathrm{S}-\mathrm{H}$ gel and small pores are mainly observed. The concrete samples made using Type I and Type $\mathrm{V}$ cement are observed to have more $\mathrm{Ca}(\mathrm{OH})_{2}$ and larger pores than those of the fly ash mixed concrete. Therefore, it is judged that the dense micro structure of the fly ash mixed concrete acts as the main factor improving durability and properties.

Pores of various sizes exist inside the concrete and 


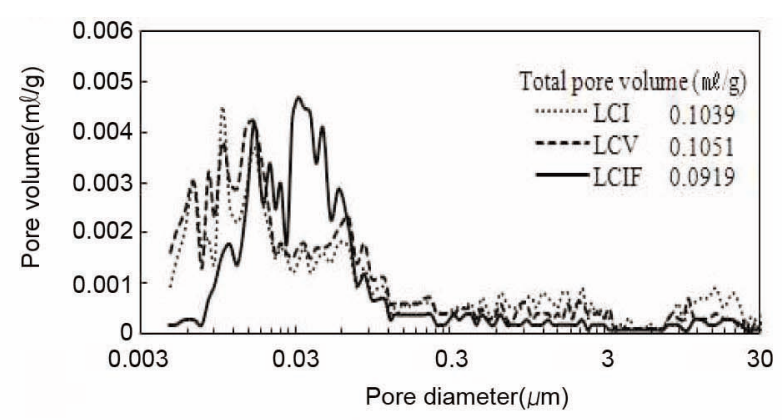

(a) LC concrete

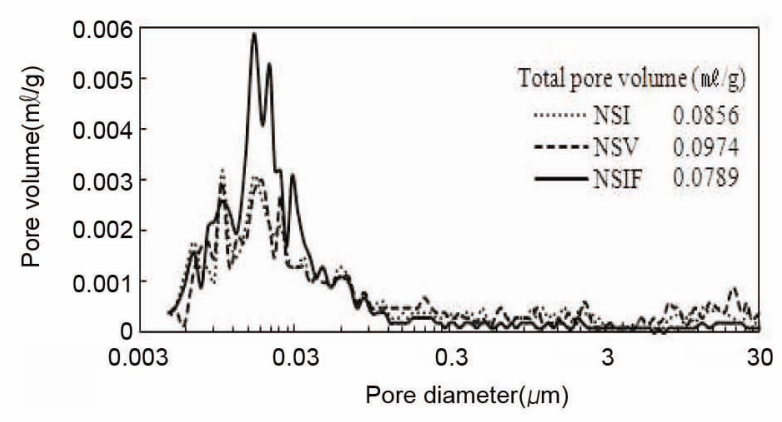

(b) NS concrete

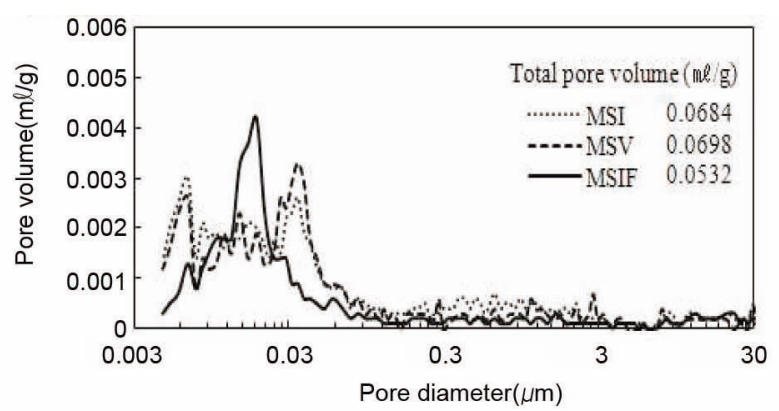

(c) MS concrete

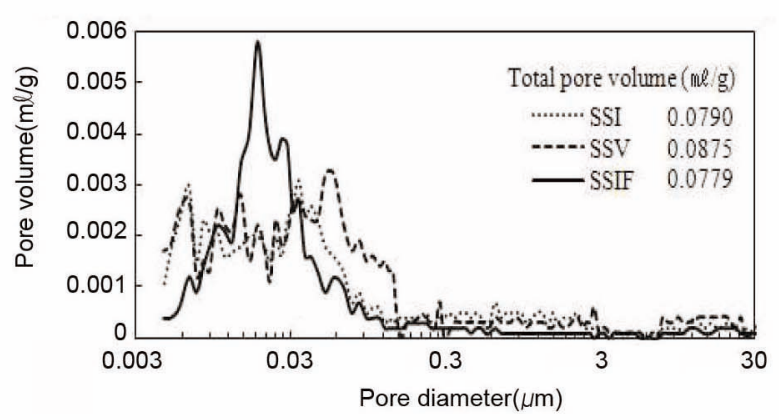

(d) SS concrete

Fig. 17. Capillary Pore Size Distribution

the pore structure plays an important role in determining the concrete quality, measured by such factors as strength and durability. The concrete pores can be classified largely into water-saturated pores and pores created during mixing. The water-saturated pores are differentiated into gel pores and capillary pores. The gel pores are about $0.001 \sim 0.003 \mu \mathrm{m}$ in diameter and the capillary pores are about $0.003 \sim 30 \mu \mathrm{m}$. Moreover, the pores created during mixing are differentiated into those formed by entrapped air occurring naturally and those formed by entrained air artificially induced by the AE agent. Entrapped air pores are about 100 1,000 $\mu \mathrm{m}$ in diameter and those of entrained air are about $30 \sim 100 \mu \mathrm{m}$. Generally, pores related to concrete strength and durability are capillary pores; these appear differently depending on the mix and the type of cement used.

Fig. 17 shows the capillary pore measurement results for concrete. These results were obtained by mercury intrusion porosimetry.

Regardless of the concrete type, the fly ash mixed concrete was shown to have the smallest total pore volume. The concrete that used Type I cement was shown to have smaller porosity than the concrete that used Type V cement. Furthermore, in comparison with the concrete that used Type I and Type V cement, the fly ash mixed concrete showed a lesser amount of pore volume and a diameter bigger than $0.1 \mu \mathrm{m}$; there was also a greater amount of pore volume of diameter $0.006 \sim 0.03 \mu \mathrm{m}$. It is deemed that the hydrates produced by the pozzolanic reaction of the fly ash fill in the pores of diameter bigger than $0.1 \mu \mathrm{m}$ and, consequently, more pores of diameter $0.006 \sim 0.03 \mu \mathrm{m}$ are created. This phenomenon is expected to continue after the age of 91 days and thereby further reduce the pores of diameter bigger than $0.1 \mu \mathrm{m}$ and increase the pores of diameter $0.006-0.03 \mu \mathrm{m}$.

Generally it is known that the greater the amount of pores inside the concrete and the larger the size of the pores, the more the strength and durability of the concrete are reduced. Since the analysis results show that when fly ash is used, the overall porosity and the formation of large size pores are less than those of the concrete using only Type I or Type V cement, fly ash is considered to act as an important factor in strength and durability improvement.

\section{CONCLUSIONS}

In this paper, the basic physical properties and durability of fly ash mixed concrete being used in Korean NPP structures are verified through tests of concrete structures. The main results are as follows: 
1) The quality assessment results verified that the fly ash used in Korean NPP concrete satisfies the base values of both KS L5401 and ASTM C618, the Korean and US standards, respectively.

2)To determine the fly ash replacement ratio, a comprehensive assessment of related technical criteria such as strength, heat of hydration, and ACI, as well as of economic feasibility, was made, and the ratio of $20 \%$ of cement weight was chosen.

3) The compressive strength of the fly ash mixed concrete during the initial age of seven days was shown to be somewhat smaller than that of the existing concrete, which used Type $\mathrm{V}$ cement. But, after an age of 28 days, the strength of the fly ash mixed concrete surpassed the strength of the concrete formed using only Type $\mathrm{V}$ cement.

4) With respect to heat of hydration and creep, the fly ash mixed concrete showed results superior to those for the existing concrete, which used Type V cement. Hence, it was determined that this concrete will display improved performance in terms of crack reduction and long-term deformation.

5)In terms of durability, in comparison with the existing concrete that used Type V cement, the fly ash mixed concrete showed superior performance with respect to chloride attack, sulfate attack and freezing and thawing resistance. As for carbonation, it was assessed that because Korean NPP structures use mainly high strength concrete with a low water-cementitious material ratio, there will be no problem securing integrity during service life.

6)Based on the micro structure analysis results of the fly ash mixed concrete, the inner pore structure was assessed to be denser than that of the existing concrete. This result agrees with other test results for strength and durability.

It can be concluded that the fly ash mixed concrete being used in Korean NPPs as an alternative to the existing Type $\mathrm{V}$ cement concrete is making a significant contribution in advancing the safety of NPPs by improving mechanical properties such as structure strength and durability. In addition, the use of fly ash mixed concrete is expected to have a substantial impact in terms of lifetime management, including construction material cost reduction and life extension.

\section{NOMENCLATURE}

$T \quad$ Adiabatic temperature rise $\left({ }^{\circ} \mathrm{C}\right)$ at time $\mathrm{t}$

$K \quad$ Maximum adiabatic temperature rise $\left({ }^{\circ} \mathrm{C}\right)$

$\alpha_{t} \quad$ Coefficient of temperature rise speed

$t_{d} \quad$ Time (days)

$X_{c} \quad$ Carbonation depth ( $\left.\mathrm{mm}\right)$ at time $\mathrm{t}$

$C \quad$ Carbon dioxide concentration (\%)

$T \quad$ Absolute temperature (K)

$H$ Relative humidity (\%) $\alpha_{c} \quad$ Coefficient of carbonation

$t_{y} \quad$ Time (years)

\section{ABBREVIATION}

NPP Nuclear Power plant

W Water

C Cement

FA Fly ash

w/cm Water-cementitious material ratio (\%)

S/a Fine aggregate percent of total aggregate by solid volume

$\mathrm{S} \quad$ Fine aggregate

G Coarse aggregate

SP Superplasticizer

AE Air-entraining agent

LC Lean concrete

LCI Lean concrete with type I cement

LCV Lean concrete with type V cement

LCIF Lean concrete with type I cement and $20 \%$ fly ash

NS Non-safety structure concrete

NSI Non-safety structure concrete with type I cement

NSV Non-safety structure concrete with type V cement

NSIF Non-safety structure concrete with type I cement and $20 \%$ fly ash

SS Safety structure concrete

SSI Safety structure concrete with type I cement

SSV Safety structure concrete with type V cement

SSIF Safety structure concrete with type I cement and $20 \%$ fly ash

MS Marine structure concrete

MSI Marine structure concrete with type I cement

MSV Marine structure concrete with type V cement

MSIF Marine structure concrete with type I cement and $20 \%$ fly ash

\section{ACKNOWLEDGMENT}

This work was supported by the Nuclear Research \& Development of the Korea Institute of Energy Technology Evaluation and Planning (KETEP) grant funded by the Korea government Ministry of Knowledge Economy. (No.2011T10020 0161)

\section{REFERENCES}

[1] ACI committee 226, Use of Fly Ash in concrete, (2000)

[2] S. Nagataki, et al., "Quality of Various Fly Ash and Fluidity of Concrete", Cement \& Concrete, vol. 472, pp. 13-19 (1986)

[ 3 ] N. Tanaka et al., "Study on Quality Management of Fly Ash Concrete", Electric Power Civil Engineering, vol. 230, pp. 69-78 (1991)

[4 ] R.T. Hemmings, "Speciation in size and density fractionated fly ash”, Mat. Res. Symp. Proc., vol. 65, pp. 91-104 (1985)

[ 5 ] H. Kamino et al., "Hardness improvement of roller compacted concrete by using pulverized fly ash", Proc. of Japan concrete institute, vol. 16, no. 1, pp. 1299-1304 (1994)

[6] J. Virtanen, "Freeze-thaw resistance of concrete containing 
blast-furnace slag, fly ash or condensed silica fume", Proc. First Int. Conf. on the Use of Fly Ash, Silica Fume, Slag and Other Mineral By-products in Concrete, Montebello,
Canada, ACI SP-79, pp. 923-942 (1983)

[ 7 ] K. Wesche, Fly Ash in concrete Properties and Performance, E \& FN SPON, pp. 104, London, (1991) 